\title{
LEARNING ANATOMY WITH MODEL MAKING ALONG WITH DISSECTION
}

\section{Vipin Garsa 1, Neeru Ghalawat *2, Ravi Kant Narayan 3, Sanjay Gupta 4, Suresh Kanta Rathee ${ }^{5}$.}

${ }^{1}$ Associate Professor, Department of Anatomy, Pandit Bhagwat Dayal Sharma PGIMS, Rohtak, Haryana, India.

${ }^{* 2}$ Senior Resident, Department of Anatomy, Pandit Bhagwat Dayal Sharma PGIM S, Rohtak, Haryana, India.

${ }^{3}$ Junior Resident, Department of Anatomy, Pandit Bhagwat Dayal Sharma PGIM S, Rohtak, Haryana, India.

${ }^{4}$ Assistant Professor, Department of Anatomy, Pandit Bhagwat Dayal Sharma PGIMS, Rohtak, Haryana, India.

${ }^{5}$ Senior Professor \& HOD, Department of Anatomy, Pandit Bhagwat Dayal Sharma PGIMS, Rohtak, Haryana, India.

\section{ABSTRACT}

Introduction: Anatomy teaching and learning is not only limited to theory classes and dissection but also to other teaching tools. One such tool is by preparing anatomy models.

Materials and Methods: The present study was carried out on $100 \mathrm{M} \mathrm{BBS} 1^{\text {st }}$ year students. In which 10 groups were made each consisting of 10 students than they were taught about the brachial and lumbar plexus made out of different colored wires prior seeing the dissected specimens. After that they were given questionnaire and their feedback was taken.

Result: In present study $98 \%$ students had the opinion that models with different color coding made better understanding of root, trunks and division. $100 \%$ found it to be more informative than 2 -d picture and more beneficial method providing them better understanding of relation of the nerves with bone and $70 \%$ found it to be more informative than you tube videos.

Conclusion: Present study reflected that learning anatomy with models along with dissection helped students more than learning anatomy via dissection alone.

KEY WORDS: Teaching Tools, Anatomy Models, Dissection, Medical Education.

Address for Correspondence: Dr. Neeru Ghalawat, Senior Resident, Department of Anatomy, Pandit Bhagwat Dayal Sharma PGIM S, Rohtak, 124001, Haryana, India.

E-Mail: drneeru465@gmail.com

\section{Access this Article online}

\section{Quick Response code}

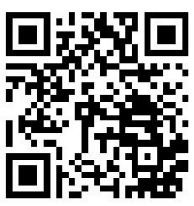

DOI: $10.16965 /$ ijar.2017.238

Web site: International Journal of Anatomy and Research

ISSN 2321-4287

www.jjmhr.org/ijar.htm

Received: 28 Apr 2017

Peer Review: 28 Apr 2017

Revised: 06 M ay 2017
Accepted: 06 Jun 2017

Published (0): 30 Jun 2017

Published (P): 30 Jun 2017

\section{INTRODUCTION}

Anatomy is the subject where learning is not possible by studying books alone, it needs to be taught by dissection and other methods also. With the advance in medical education, tools of teaching anatomy are expanding. One of the 
learning tool is model making [1]. There are number of review studies which have compared dissection to the use of prosected specimens (in which students can study whole or parts of cadavers dissected by anatomy staff in advance) [2] and other teaching tool [3]. Although not straight forward, the results seem to be slightly in favour of dissection. However, research has also shown that a dissection is not a uniform learning experience [4]. Different students have different approaches in dealing with dissection, therefore undergoing divergent learning experiences, which may result in differences in amount and form of knowledge between individuals [5]. Biasutto et al [6] found better results for students who dissected cadavers, but reported the best scores for the group of students who learned by both dissection and use of computer resources.

While the less complex structures can be studied from a textbook or cadaver material, it is possible that students may get a better understanding of more complex anatomical structures (e.g. bones of the skull, the brain, course of a blood vessel) from virtual models [5]. Patel et al. [7] described these virtual models to be very expensive which inhibited their full or partial substitution of cadaver dissection.

Although you tube video may be a very popular learning method, but some students perceive it as challenging, time consuming and frustrating as other students perceive cadaver dissection to be. When considering you tube as an alternative or additional learning method, it seems indispensable that the involved faculty guides students in the search and selection of the best resources [8].

\section{MATERIALS AND METHODS}

Present study was conducted in department of Anatomy Pt. B. D. Sharma Post Graduate Institute of Medical Sciences Rohtak. The proposed study was carried out with 100 students of MBBS $1^{\text {st }}$ year prof. who were willing to participate in the study. Ten groups were made each consisting of 10 students. In present exercise models of brachial and lumbar plexus were made out with different colored wires to provide different color coding for each nerve root. Than each group was taught about brachial and the lumbar plexus on the model and after that they were taken to the dissection hall to see the dissected specimens. Than after that questionnaire was given to each student and their response towards the activity was segregated.

Fig. 1: Showing the Brachial plexus.

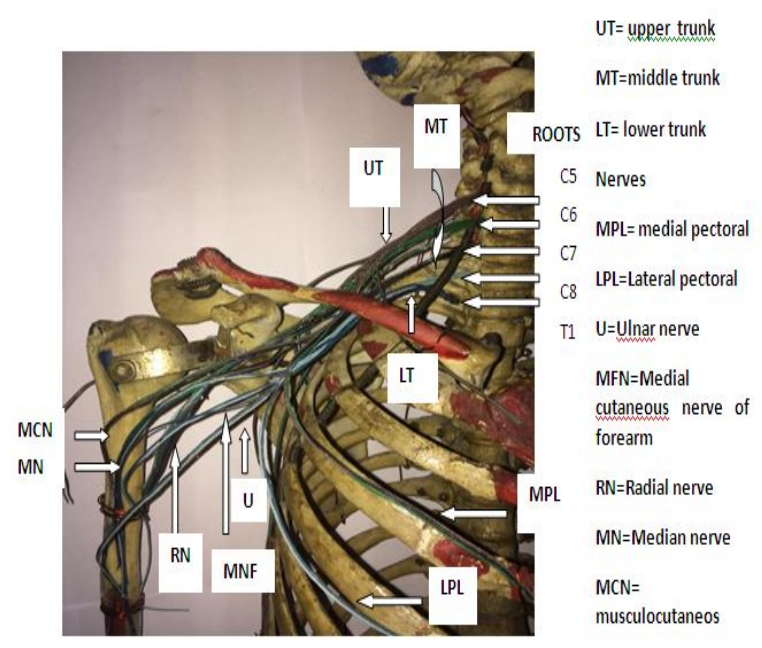

Fig. 2: Showing the lumbar plexus.

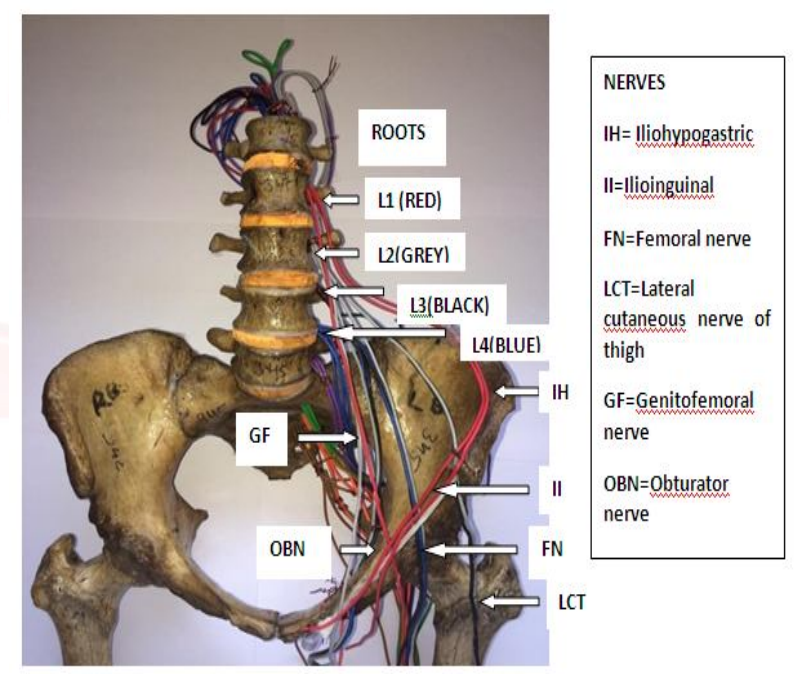

Fig.3: Showing the model making.

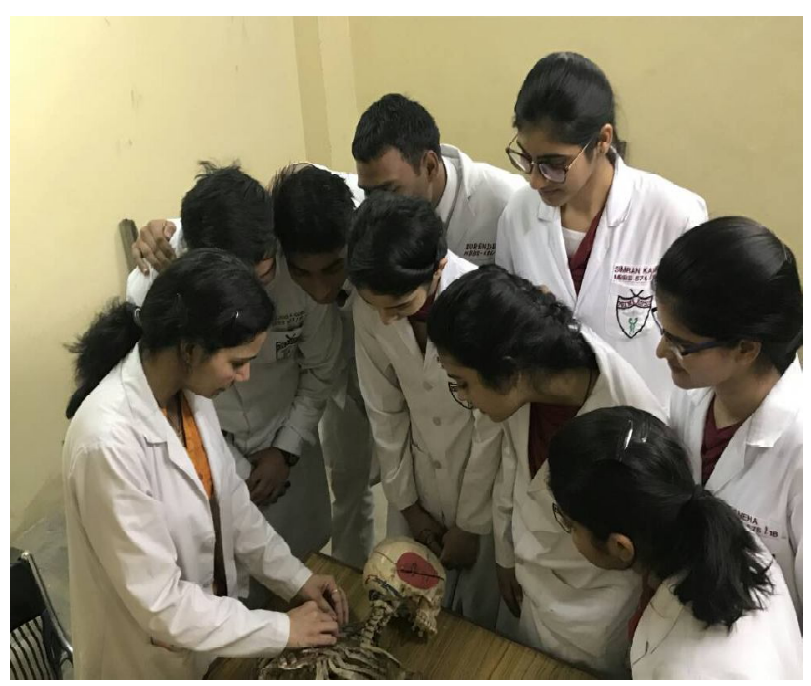

3994 


\section{RESULTS}

Table 1: Questionnaire, Total participants $=100$ students.

\begin{tabular}{|c|l|c|c|}
\hline \multirow{2}{*}{ S.no Questions } & \multicolumn{1}{|c|}{ Response } \\
\cline { 3 - 4 } & & \multicolumn{1}{|c|}{ Yes } & No \\
\hline 1 & $\begin{array}{l}\text { Did the brachial plexus/ lumbar plexus made out of different colored wires made } \\
\text { better understanding of the roots, trunk and division? }\end{array}$ & $98 \%$ & $2 \%$ \\
\hline 2 & $\begin{array}{l}\text { Did 3-d model of brachial plexus/ lumbar plexus make better understanding of } \\
\text { relation of nerves with bones in upper limb? }\end{array}$ & $100 \%$ & 0 \\
\hline 3 & Was it more informative than 2-d pictures of the text book? & $100 \%$ & 0 \\
\hline 4 & Do you find this way of studying more beneficial? & $100 \%$ & 0 \\
\hline 5 & Did seeing model prior going to dissection made better understanding? & $94 \%$ & $6 \%$ \\
\hline 6 & Was it more informative than videos seen on you tube? & $70 \%$ & $30 \%$ \\
\hline
\end{tabular}

\section{DISCUSSION}

Anatomy teaching and learning is not only limited to theory classes and dissection but also to other teaching tools. One such tool is by preparing anatomy models [1].

Cadaver dissection as a learning method is no single method for teaching anatomy. Strategies such as constructive learning (occasion for repetition and scaffolding), collaborative learning (interaction between learners), contextual learning (learning in context) are crucial when it comes to knowledge acquisition and retention [9].

Learning anatomy may benefit from "directed self learning" (in contrast to self directed learning), suggesting self study should be guided by experts in the subject of both anatomy and medicine [10].

In present study students were shown the models made out of different colored wires prior going to dissection hall.

In present exercise $98 \%$ students had the opinion that models made out of different colored wires made better understanding of roots, trunks and division while $2 \%$ students had different opinion, as compared to M allashetty $\mathrm{N}$ et al. [1] in which he reported $95 \%$ students with positive response in understanding of 3-d aspect of any structure with the help of models.

$100 \%$ students had positive response that these models made better understanding of relations of nerve with bone and also to be more informative than the 2-d pictures of text book.

$100 \%$ students favored this way of studying and found it to be more beneficial than dissection alone. $70 \%$ students found it to be more informative than the you tube videos while $30 \%$ were with different response.

Although opinions may differ as to its scope, there is a general consensus that medical students definitely cannot do without anatomical knowledge, consequently without anatomical education. However, in medical education today, the key question regarding anatomy education increasingly focuses on how education can be made as effective as possible. Therefore, it is important that future research investigates what and how students learn from dissection and other teaching methods [5].

So the present study based on the students feedback, towards learning anatomy on the models along with dissection helped the students and also reflected the improvement in quality of teaching.

\section{CONCLUSION}

Present study reflected that learning anatomy with models along with dissection helped students more than learning anatomy via dissection alone.

\section{Conflicts of Interests: None}

\section{REFERENCES}

[1]. M allashetty $\mathrm{N}$ et al. M odel making exercise - $\mathrm{A}$ new tool for teaching and learning anatomy and perception of students towards it. J of Edu Resand Med Teac. 2015;3(1):34-36.

[2]. Winkelmann A. Anatomical dissection as a teaching method in medical school: a review of the evidence. Med Educ. 2007;41:15-22. 
[3]. Berman EM, Van der Vleuten CP, Scherpbier AJ. Why don't they know enough about anatomy? A narrative review. M ed Teach. 2011;33:403-9.

[4]. Winkelmann A, Hendrix S, Kiessling C. What do students actually do during a dissection course? First steps towards understanding a complex learning experience. Acad M ed. 2007;82:989-95.

[5]. Bergman EM. Discussing dissection in anatomy education. Perspect M ed Educ. 2015;4:211-213.

[6]. Biasutto EM, Caussa LI, Criado del Rio LE. Teaching anatomy: cadavers vs. computers? Ann Anat. 2006;188:187-90.

[7]. Patel S, M auro D, Fenn J, Sharkey D, Jones C. Is dissection the only way to learn anatomy? Thoughts from students at a non-dissecting based medical school. Perspect Med Educ. 2015; 5. DOI: 10.1007/s 40037-015-0206-8.
[8]. Raikos A, Waidyasekara P. how useful is YouTube in learning heart anatomy? Anat Sci Educ. 2008;1:1848.

[9]. Bergman EM, Prince KJ, Drukker J, Van der Vleuten CP, Scherpbier AJ. How much anatomy is enough? Anat Sci Educ. 2008;1:184-8.

[10]. Regan de Bere S, M attick K. From anatomical 'competence' to complex capability. The views and experiences of UK tutors on how we should teach anatomy to medical students. Adv Health Sci Educ Theory Pract. 2010;15:573-85.

How to cite this article:

Vipin Garsa, Neeru Ghalawat, Ravi Kant Narayan, Sanjay Gupta, Suresh Kanta Rathee. LEARNING ANATOMY WITH MODEL MAKING ALONG WITH DISSECTION. Int J Anat Res 2017;5(2.3):3993-3996. DOI: 10.16965/ijar.2017.238 